\title{
Face mask spirometry and respiratory pressures in normal subjects
}

\author{
M. Wohlgemuth*, E.L. van der Kooi*, J.C. Hendriks", G.W. Padberg*, H.T. Folgering
}

Face mask spirometry and respiratory pressures in normal subjects. M. Wohlgemuth, E.L. van der Kooi, J.C. Hendriks, G. W. Padberg, H.T. Folgering. (C) ERS Journals Ltd 2003.

ABSTRACT: Spirometry and maximal respiratory pressures are pulmonary function parameters commonly used to evaluate respiratory function. Prediction values are available for conventional lung function devices using a standard tube or flanged type of mouthpiece connection. This equipment is not suitable for patients with facial or buccal muscle weakness, because of air leakage around the mouthpiece. A face mask was used for the portable lung function devices used in the neuromuscular department.

The aim of this study was to compare the face mask and the conventional mouthpiece for the measurement of spirometry and of respiratory pressures in 22 healthy subjects.

Values obtained with the conventional mouthpiece differed significantly from values obtained with the face mask. With the mask, forced vital capacity and forced expiratory volume in one second were $200 \mathrm{~mL}$ lower, and maximal expiratory pressure was $3.2 \mathrm{kPa}$ lower than with the mouthpiece. Subsequently, new prediction values for face mask spirometry and maximal respiratory pressures were obtained from 252 other healthy subjects, from which new prediction equations were derived.

It was concluded that the face mask connection to the lung function device is a valid alternative, is easy to use and is most useful to monitor changes in patients. This study confirms the importance of appropriate prediction equations, depending on subjectinstrument interfaces.

Eur Respir J 2003; 22: 1001-1006.
*Dept of Neurology, University Medical Centre Nijmegen, "Dept of Epidemiology and Biostatistics, University of Nijmegen, Nijmegen, and "Dept of Pulmonary Diseases, University of Nijmegen, Medical Centre Dekkerswald, Groesbeek, the Netherlands.

Correspondence: M. Wohlgemuth, University Medical Centre Nijmegen, Dept of Neurology, Reinier Postlaan 4, 6500 HB Nijmegen, the Netherlands.

Fax: 31243541122

E-mail: M.Wohlgemuth@neuro.umcn.nl

Keywords: Face mask

reference values

respiratory pressures

spirometry

Received: March 132003

Accepted after revision: July 112003
Measurement of vital capacity (VC) and maximal respiratory pressures is commonly used to evaluate respiratory function and respiratory muscle strength in patients with chronic obstructive pulmonary disease or neuromuscular diseases [1-3]. Portable devices are useful for rapid and simple assessment of respiratory function in the office and at the bedside. Prediction values of spirometry and maximal respiratory pressures are available for portable and nonportable devices with a standard tube or a flanged type of mouthpiece connection [4-8]. This equipment is only suitable for subjects capable of making a good seal with their lips around the mouthpiece. However, patients with neuromuscular diseases characterised by facial or bulbar muscle weakness, e.g. amyotrophic lateral sclerosis, myasthenia gravis, myotonic dystrophy and facioscapulohumeral muscular dystrophy, often cannot effectively seal the lips around the mouthpiece, especially during forced manoeuvres such as spirometric and maximal respiratory pressure measurements $[9,10]$. In these cases, the conventional equipment with a tube or flanged type of mouthpiece is not adequate to evaluate respiratory muscle function. Therefore, a face mask adjusted to a portable spirometer and manometer was used to minimise air leakage in neuromuscular patients.

The objective of this study was two-fold. First, possible differences in measurements between the original devices with the conventional mouthpiece and the face mask-adjusted devices were studied in healthy subjects. Secondly, a study to render new prediction equations for face mask spirometry and maximal respiratory pressures in healthy subjects was conducted.

\section{Methods}

\section{Subjects}

Healthy volunteers $(n=22)$ were studied using the face mask and the conventional mouthpiece, in a randomised order, for comparison of the connection to the instruments for measurements of spirometry and maximal respiratory pressure. Using the face mask, 20 healthy volunteers performed spirometry and maximal respiratory pressure measurements at day 1 and day 4, to study the within-subject variance.

In 15 subjects, the spirometric and the maximal respiratory pressure measurements of two different sizes of masks with different volumes were compared (Leardal mask number 4 and Leardal mask number 5, with volumes of 210 and $150 \mathrm{~mL}$, respectively; Leardal, London, UK).

Subsequently, 252 additional healthy subjects were recruited to render new prediction equations for the face mask spirometry and face mask maximal respiratory pressures. Nearly all subjects $(99 \%)$ were partners accompanying neurological patients visiting the outpatient clinic and all gave their informed consent. Subjects were recruited consecutively, until 20 males and 20 females in each decade from 18-80 yrs were included. Exclusion criteria comprised ages of $<18$ yrs, cardiopulmonary and neuromuscular disease, any chronic disease and use of medication except for sporadic analgesic use and use of oral contraceptives. Data on sex, age, height, weight, smoking status and the lung function parameters were recorded. 


\section{Spirometry}

Forced vital capacity (FVC), forced expiratory volume in one second (FEV1) and the FEV1/FVC ratio were measured with a Morgan Spirometer (type PM2000; P.K. Morgan Ltd, Rainham, UK). Calibration checks were performed daily with a $3-\mathrm{L}$ syringe. Sitting subjects were connected to the spirometer via the conventional mouthpiece, which is a cardboard tube, or via a rigid noncompressable face mask (a Leardal adult mask number 5). All subjects were unfamiliar with the techniques and all subjects received the same instructions. The spirometer with the face mask was held and pressed tightly against the subject's face by the investigator, while the conventional device using the cardboard tube was held by the subject. At least three efforts were performed until two readings within a 5\% range were obtained. An interval of 1 min was taken between two efforts. The highest combination of FVC and FEV1 of one effort was recorded. The manoeuvre was rejected if the investigator noticed any air leakage around the mask.

\section{Maximal respiratory pressures}

Maximal inspiratory mouth pressure (MIP) at residual volume and maximal expiratory mouth pressure (MEP) at total lung capacity were obtained in sitting subjects connected to a Morgan manometer (type Pmax) containing a small leak (internal diameter $2 \mathrm{~mm}, 2 \mathrm{~cm}$ length) preventing buccal muscles from producing significant pressures and preventing closing of the glottis. The conventional flanged mouthpiece was tested versus the face mask. This measuring system was calibrated monthly with a water manometer. The system never had to be corrected during the study. The accuracy of the device is to $4 \mathrm{cmH}_{2} \mathrm{O}$. All subjects received the same instructions. Pressures were measured with a noseclip when using the mouthpiece. Pressures had to be maintained for $1 \mathrm{~s}$ and the plateau level was recorded. The highest pressure of at least three efforts with a maximum of $5 \%$ variability was documented. If close observation and listening indicated any air leakage around the mask, or if maximal pressure was not maintained for at least $1 \mathrm{~s}$, the manoeuvre was rejected. All experiments were conducted by one experienced investigator.

\section{Statistical methods}

One way analysis of variance was used to estimate the within-subject SD, and the corresponding coefficient of variation $(\mathrm{CV})$, of the repeated values measured at day 1 and day 4. The dependent variables were FVC, FEV1, MIP and MEP, and the independent random variable was the subject. The statistical method for assessing the agreement between the face mask measurements and the conventional mouthpiece measurements was performed according to BLAND and ALTMAN [11], using each spirometric and respiratory measurement separately. Multiple regression analysis was performed to derive prediction equations for each spirometric or respiratory measurement separately. The dependent variable was the spirometric or respiratory measurement, and the independent variables in each regression model were sex, age, height and weight. The prediction equations obtained were compared with the literature and for the ease of interpretation, those from the literature that were presented by sex were combined into one equation.

\section{Results}

In the first part of the study 22 subjects (nine males and 13 females; mean age $33.4 \pm 9.4$ yrs, height $176 \pm 8.5 \mathrm{~cm}$ and weight $75 \pm 5 \mathrm{~kg}$ ) performed two sets of measurements, one using the conventional mouthpiece and one using the face mask connection to the devices. Table 1 shows the results of the comparison of the two different mouthpiece connections for spirometric and maximal respiratory pressures. Values obtained with the conventional mouthpiece were significantly higher than values obtained with the face mask (paired t-test, $\mathrm{p}<0.001$ ), except for the MIP (paired t-test, $\mathrm{p}=0.26$ ). The (differences in) means are not solely used to compare methods. Also the variances are of interest. Therefore, the ratio of SD using the face mask to the SD using the mouthpiece was calculated. The between-subject variance of all spirometry and all respiratory measurements with the mouthpiece were greater compared with those obtained with the face mask. The between-subject variance of the FVC, FEV1, FEV1/FVC and MIP was $20-82 \%$ higher using the conventional mouthpiece, while for the MEP the variance using the mouthpiece was 3.28-times higher then using the face mask device (table 1).

Bland and Altman plots of the differences and their means between mouthpiece and mask showed a lack of agreement. The plots showed that the difference increases as the FVC, FEV1 and MEP increase, while this is less for MIP. Figure 1 shows the plots of FEV1 and MIP. Subjects with the largest differences between mouthpiece and mask were those who produced the highest values measured with the mouthpiece connection.

For the follow-up of neuromuscular patients, the withinsubject variation is needed. Using the face mask, the within-subject CV of FVC, FEV1, MEP and MIP, estimated from repeated measurements at day 1 and day 4 in a group of 20 healthy subjects, was $1.4 \%, 2.1 \%, 6.4 \%$ and $5.4 \%$, respectively. From these results, it was concluded that the pressure measurements obtained using the conventional mouthpiece and the face mask connection cannot be used interchangeably.

Additional measurements with two different masks with different volumes showed no statistically significant differences for mean differences in FVC (0.01 L, p=0.73), FEV1 (0.06 L, p=0.19), MIP (0.04 kPa, p=0.76) and MEP (0.19 kPa, $\mathrm{p}=0.26)$.

Subsequently, new reference values for spirometry and manometry variables using the face mask-adjusted devices were derived from 252 subjects, 126 males and 126 females. Table 2 shows the mean \pm sD height and weight by age group and by sex. There were 64 smokers or former smokers, 34 males and 30 females. Smoking did not have a significant contribution to the prediction equations, therefore smokers and former smokers were included in the analyses.

Table 3 presents the spirometric and maximal respiratory pressure values by age group and by sex. The influence of age and sex is strong on the mean values of FVC, FEV1, MIP and MEP. Decreasing mean values of FVC, FEV1, MIP and MEP were observed with increasing age, and females systematically showed lower values in all variables, implying a strong sex effect. Tables 4 and 5 show the regression equations of multiple regression analyses of all variables. All variables were influenced by age and sex, except for the FEV1/FVC ratio with only age as a predictor. The prediction equations for the FVC and FEV1 also had height as an explanatory variable. The maximal respiratory pressures were influenced by weight, age and sex (table 5).

Although prediction equations of both FVC and FEV1 were in line with those reported in the literature, considering 
Table 1. - Spirometry and maximal respiratory pressures comparison of the conventional mouthpiece and face mask connection in 22 subjects

\begin{tabular}{lccccc}
\hline Function parameter & Tube & Mask & $\Delta$ Tube-mask $^{\#}$ & Variance tube/mask $^{\text {厂 }}$ & Correlation mean/ $\Delta$ tube-mask \\
\hline FVC L & $5.8 \pm 1.4$ & $5.6 \pm 1.2$ & $0.2 \pm 0.2^{* *}$ & 1.20 & $0.52^{*}$ \\
FEV1 L & $5.3 \pm 1.2$ & $5.1 \pm 1.1$ & $0.2 \pm 0.2^{* *}$ & 1.21 & $0.61^{*}$ \\
FEV1/FVC & $0.91 \pm 0.04$ & $0.91 \pm 0.037$ & $0.001 \pm 0.02$ & 1.82 & 0.13 \\
MEP kPa & $13.7 \pm 4.3$ & $11.4 \pm 2.4$ & $2.2 \pm 2.5^{* *}$ & 3.28 & $0.78^{*}$ \\
MIP kPa & $9.2 \pm 2.5$ & $8.9 \pm 2.2$ & $0.3 \pm 1.2$ & 1.31 & 0.28 \\
\hline
\end{tabular}

Data are presented as mean \pm SD unless otherwise stated. FVC: forced vital capacity; FEV1: forced expiratory volume in one second; MEP: maximal expiratory pressure; MIP: maximal inspiratory pressure; tube: conventional spirometer or manometer; mask: face mask-adjusted spirometer and manometer. ${ }^{\#}$ : difference in mean between tube and mask; ${ }^{\natural}$ : ratio of the tube variance to the mask variance. *: $\mathrm{p}<0.05$ using Pearson rank correlation test; $* *: \mathrm{p}<0.01$ using t-test.

the SE of the regression coefficients (table 4), the predicted values of an average male and an average female were consistently higher using the face mask (table 6) as with the ratio of FEV1/FVC. A direct comparison of the prediction equation for MEP values as well for the MIP values was not possible because of the different explaining variables (height and weight) in the equations. However, the predicted values using the face mask and those presented in the literature were similar considering the residual SD. Table 6 shows the predicted values of an average adult male and an average adult female.
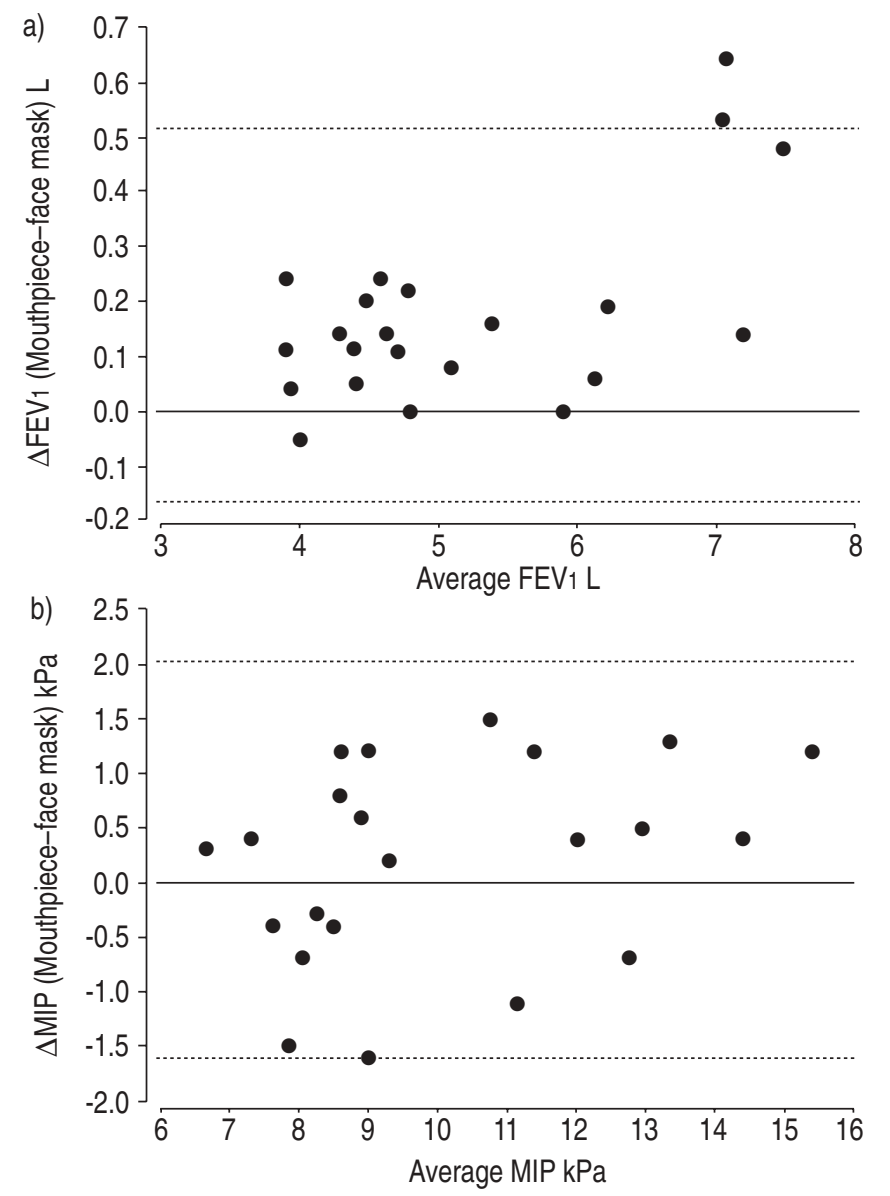

Fig. 1.-Bland and Altman plots of the difference against the average of the conventional mouthpiece and the face mask for a) the forced expiratory volume in one second $\left(\mathrm{FEV}_{1}\right)$ and b) the maximal inspiratory mouth pressure (MIP). The solid line indicates no difference and the dotted lines represent the mean $\pm 1.96 \mathrm{SD}$.

\section{Discussion}

This study demonstrated that face mask adjustment is a valid and easy method to measure respiratory function and respiratory muscle strength in healthy persons. Comparison of the conventional mouthpiece with the face mask connection to the instruments showed that they cannot be used interchangeably. New prediction equations for face maskadjusted pulmonary portable devices were derived from 252 healthy subjects.

Table 2. - Height and weight by age group and by sex

$\begin{array}{llllll}\text { Age yrs } & \text { Subjects n } & \text { Sex } & \text { Height } \mathrm{cm} & \text { Weight kg } & \text { Smokers \% }\end{array}$

\begin{tabular}{lcclll}
\hline $18-29$ & 20 & M & $182.6 \pm 6$ & $79.7 \pm 11$ & 25 \\
& 23 & F & $169.6 \pm 8$ & $67.1 \pm 8$ & 17 \\
$30-39$ & 20 & M & $183.9 \pm 8$ & $85.2 \pm 15$ & 25 \\
& 20 & F & $169.7 \pm 9$ & $67.3 \pm 10$ & 15 \\
$40-49$ & 25 & M & $180.2 \pm 8$ & $85.9 \pm 13$ & 20 \\
& 21 & F & $167.9 \pm 7$ & $71.9 \pm 12$ & 38 \\
$50-59$ & 20 & M & $179.7 \pm 6$ & $83.2 \pm 11$ & 40 \\
& 22 & F & $167.5 \pm 6$ & $68.4 \pm 11$ & 36 \\
$60-69$ & 21 & M & $176.6 \pm 6$ & $78.5 \pm 10$ & 28 \\
& 20 & F & $164.4 \pm 7$ & $66.1 \pm 8$ & 25 \\
$\geqslant 70$ & 20 & M & $175.3 \pm 7$ & $74.7 \pm 7$ & 25 \\
& 20 & F & $164.0 \pm 6$ & $67.0 \pm 7$ & 20 \\
\hline
\end{tabular}

Data are presented as mean \pm SD unless otherwise stated. Smokers: smokers and former smokers; M: male; F: female. Of the total number of smokers, $39 \%$ stopped smoking $\geqslant 0.5$ yrs ago.

Table 3. - Spirometry and maximal respiratory pressures by sex and by age group

Age Sex FVC L FEV1 L FEV1/FVC \% MIP kPa MEP kPa yrs

\begin{tabular}{lcrrrrr}
\hline $18-29$ & M & $6.4 \pm 0.5$ & $5.9 \pm 0.4$ & $93 \pm 4$ & $11.3 \pm 1.8$ & $14.6 \pm 2.4$ \\
& F & $4.6 \pm 0.7$ & $4.1 \pm 0.7$ & $90 \pm 4$ & $8.8 \pm 1.4$ & $10.7 \pm 2.1$ \\
$30-39$ & M & $6.2 \pm 0.8$ & $5.5 \pm 0.9$ & $89 \pm 5$ & $11.0 \pm 3.0$ & $14.7 \pm 3.9$ \\
& F & $4.5 \pm 0.9$ & $4.0 \pm 0.8$ & $90 \pm 4$ & $8.0 \pm 1.7$ & $10.8 \pm 2.1$ \\
$40-49$ & M & $5.7 \pm 1.1$ & $5.0 \pm 0.9$ & $89 \pm 4$ & $10.1 \pm 1.8$ & $14.0 \pm 2.4$ \\
& F & $4.3 \pm 1.0$ & $3.7 \pm 0.8$ & $86 \pm 6$ & $7.2 \pm 1.3$ & $10.2 \pm 2.2$ \\
$50-59$ & M & $5.1 \pm 0.8$ & $4.4 \pm 0.7$ & $87 \pm 4$ & $9.5 \pm 2.0$ & $12.5 \pm 3.0$ \\
& F & $4.0 \pm 0.6$ & $3.5 \pm 0.6$ & $88 \pm 4$ & $7.5 \pm 1.2$ & $9.4 \pm 1.6$ \\
$60-69$ & M & $4.6 \pm 0.7$ & $3.9 \pm 0.6$ & $85 \pm 4$ & $7.9 \pm 1.3$ & $11.1 \pm 2.1$ \\
& F & $3.1 \pm 0.5$ & $2.7 \pm 0.4$ & $86 \pm 6$ & $6.8 \pm 0.9$ & $8.8 \pm 1.3$ \\
$\geqslant 70$ & M & $3.8 \pm 0.7$ & $3.2 \pm 0.7$ & $85 \pm 5$ & $7.5 \pm 1.2$ & $9.5 \pm 1.6$ \\
& F & $2.6 \pm 0.4$ & $2.2 \pm 0.3$ & $83 \pm 6$ & $6.3 \pm 0.6$ & $7.7 \pm 0.8$ \\
\hline
\end{tabular}

Data are presented as mean \pm SD unless otherwise stated. FVC: forced vital capacity; FEV1: forced expiratory volume in one second; MIP: maximal inspiratory pressure; MEP: maximal expiratory pressure; $\mathrm{M}$ : male; F: female. 
Table 4. - Prediction equations for face mask spirometry for adults aged 18-80 yrs

\begin{tabular}{|c|c|c|c|}
\hline & & RSD & $\mathrm{R}^{2}$ \\
\hline $\begin{aligned} \mathrm{FVC}= & =3.92-(0.039 \times \mathrm{A})+(0.058 \times \mathrm{H})+(0.76 \times \mathrm{S}) \\
& (1.147)(0.003) \quad(0.006) \quad(0.116)\end{aligned}$ & (1) & 0.63 & $78 \%$ \\
\hline $\mathrm{FVCq}=-2.89-(0.026 \times \mathrm{A})+(0.044 \times \mathrm{H})-(1.45 \times \mathrm{S})+(0.013 \times \mathrm{H} \times \mathrm{S})$ & (2) & $0.61^{\#} / 0.43^{\bullet}$ & NA \\
\hline $\begin{array}{c}\mathrm{FEV} 1=-2.84-(0.035 \times \mathrm{A})+(0.047 \times \mathrm{H})+(1.29 \times \mathrm{S})-(0.011 \times \mathrm{S} \times \mathrm{A}) \\
(1.01) \quad(0.003) \quad(0.006) \\
(0.25)\end{array}$ & (3) & 0.55 & $81 \%$ \\
\hline FEV1q $=-2.60-(0.025 \times \mathrm{A})+(0.040 \times \mathrm{H})+(0.11 \times \mathrm{S})+(0.003 \times \mathrm{H} \times \mathrm{S})-(0.004 \times \mathrm{S} \times \mathrm{A})$ & (4) & $0.51^{\#} / 0.38^{\bullet}$ & NA \\
\hline $\begin{array}{r}\mathrm{FEV} 1 / \mathrm{FVC}=94.70-(0.14 \times \mathrm{A}) \\
(1.02) \quad(0.02)\end{array}$ & (5) & 4.65 & $23 \%$ \\
\hline $\mathrm{FEV} 1 / \mathrm{FVCq}=89.10-(0.19 \times \mathrm{A})-(1.89 \times \mathrm{S})+(0.01 \times \mathrm{S} \times \mathrm{A})$ & (6) & $7.17^{\#} / 6.51^{\bullet}$ & NA \\
\hline
\end{tabular}

RSD: residual standard deviation; $\mathrm{R}^{2}$ : the percentage explained variance; FVC: forced vital capacity (L); A: age (yrs); H: standing height (cm); S: sex; q: prediction equations according to [6] presented by sex (S) are combined to one equation (this can easily be checked using S=1 for obtaining the separate equation for males and $\mathrm{S}=0$ for females); FEV1: forced expiratory volume in one second (L); NA: not available (see [6]). "\#: males; ": females.

Data in the brackets underneath equations 1,3 and 5 are SE values of the regression coefficients.

Table 5. - Prediction equations of maximal respiratory pressures for adults aged $18-80 \mathrm{yrs}$

\begin{tabular}{crr}
\hline & RSD & $\mathrm{R}^{2}$ \\
\hline $\mathrm{MEP}=9.887-(0.055 \times \mathrm{A})+(0.035 \times \mathrm{W})+(5.224 \times \mathrm{S})-(0.049 \times \mathrm{S} \times \mathrm{A})$ & $(6)$ & 2.23 \\
$(1.083)(0.011) \quad(0.013) \quad(0.897) \quad(0.017)$ & $\mathrm{NA}$ & $50 \%$ \\
$\mathrm{MEPw}=0.35+(17.65 \times \mathrm{S})-(0.091 \times \mathrm{A} \times \mathrm{S})+(0.055 \times \mathrm{H})-(0.055 \times \mathrm{H} \times \mathrm{S})$ & $\mathrm{NA}$ \\
$\mathrm{MIP}=7.224-(0.040 \times \mathrm{A})+(0.032 \times \mathrm{W})+(3.745 \times \mathrm{S})-(0.041 \times \mathrm{S} \times \mathrm{A})$ & $(8)$ & $51 \%$ \\
$(0.766)(0.008) \quad(0.009) \quad(0.635) \quad(0.012)$ & $(9)$ & $\mathrm{NA}$ \\
$\mathrm{MIPw}=-4.3+(18.5 \times \mathrm{S})-(0.103 \times \mathrm{A} \times \mathrm{S})+(0.071 \times \mathrm{H})-(0.071 \times \mathrm{H} \times \mathrm{S})$ & $\mathrm{NA}$ \\
\hline
\end{tabular}

RSD: residual standard deviation; $\mathrm{R}^{2}$ : the percentage explained variance; MEP: maximal expiratory pressure ( $\mathrm{kPa}$ ); $\mathrm{A}$ : age (yrs); W: weight (kg); $\mathrm{S}$ : sex; w: prediction equations according to [8] presented by sex (S) are combined to one equation (this can easily be checked using $\mathrm{S}=1$ for obtaining the separate equation for males and $\mathrm{S}=0$ for females); MIP: maximal inspiratory pressure (kPa); NA: not available (see [8]). Data in the brackets underneath equations 7 and 9 are SE values of the regression coefficients.

Although, the results of the spirometric measurements with the tube mouthpiece are statistically significantly higher than with the face mask connection, a difference in VC of 100-200 mL may not be of clinical importance for a single measurement. However, in the lower ranges a difference of $200 \mathrm{~mL}$ may be worth noticing, especially in follow-up measurements within neuromuscular patients for early detection of respiratory failure. From the literature, it is known that the average within-subject SD of repeated measurements of the $\mathrm{VC}$ is $90-200 \mathrm{~mL}$ [6]. An acceptable low CV for the FVC of $1.4 \%$ was found, showing that the face mask measurements have an excellent reproducibility. The differences in FVC and FEV1 between tube and mask are very

Table 6.-Predicted spirometric values and maximal respiratory pressures calculated by the present study and references [6] and [8], respectively, for an average adult male (M) and an average adult female (F)

\begin{tabular}{lcccc}
\hline & Sex & Face mask & Ref. [8] & Ref. [6] \\
\hline MEP kPa & M & 13.4 & 14.4 & \\
& F & 10.1 & 9.7 & \\
MIP kPa & M & 10.0 & 10.1 & \\
& F & 7.9 & 7.8 & \\
FVC L & M & 5.14 & & 4.31 \\
& F & 4.38 & & 3.55 \\
FEV1 L & M & 4.58 & & 3.66 \\
& F & 3.75 & & 3.20 \\
FEV1/FVC & M & 89.1 & & 80.0 \\
& F & 89.1 & & 81.5 \\
\hline
\end{tabular}

MEP: maximal expiratory pressure; MIP: maximal inspiratory pressure; FVC: forced vital capacity; FEV1: forced expiratory volume in one second. The average values for both $\mathrm{M}$ and $\mathrm{F}$ subjects were $40 \mathrm{yrs}$ of age, height $170 \mathrm{~cm}$ and weight $70 \mathrm{~kg}$. similar, suggesting that the main differences occur in the beginning of the forced manoeuvres. To investigate the possibility of the influence of the volume of the mask being used, additional measurements were performed to test two different masks with different volumes. The results showed no significant differences between the two masks for FVC and FEV1 and they can be used interchangeably.

The only difference in measurement conditions was that in the mouthpiece situation the subjects themselves held the instruments, whereas in the face mask situation, the instrument was held by the observer. It is possible that the subjects did not make full maximal efforts in the latter situation.

The maximal respiratory pressures obtained with the flanged mouthpiece were higher than the ones obtained with the face mask. Activation of buccal muscles may explain the differences, in spite of the small leak in the pressure transducer. The between-subject variance using the flanged type of mouthpiece was much higher compared with the face mask variance. For the face mask experiments, it was decided that the investigator should hold the instrument. The investigator had to press the mask tightly against the subjects face to prevent air leakage. The impression was that, especially during the forced manoeuvres i.e. during the FVC and MEP measurements, a few subjects appeared to hold back. This could have influenced the predicted values for these manoeuvres negatively, especially for the higher values. Another probable explanation can be the relative fixation of the head when placing the mask against the subject's face by the investigator, whereas in the mouthpiece measurements the instruments were held by the subjects. The slight head movement of the subjects in the mouthpiece group may have influenced the measurements and resulted in higher values. Both the buccal muscles activation, the hold-back hypothesis and head fixation may explain the differences in values and in variance particularly in the higher ranges. 
There were no significant differences between mask number 4 and number 5 for the MIP and MEP measurements. For the pressure measurements, it is suggested that the size and type of mask is not crucial. In the second part of the study, new reference values were obtained in healthy adults, and new prediction equations derived by multivariate regression analysis. For the spirometry, the same explanatory variables in the equations as those in the prediction equations of QUANJER et al. [6] are of importance. The results of both conventional spirometry and face mask spirometry were higher compared with the predicted reference values of QUANJER et al. [6]. In males, the values of FVC varied from $20 \%$ higher at the age of 20 yrs to $8 \%$ higher at the age of 70 yrs compared with the predicted values of QUANJER et al. [6]. The same pattern is seen in females at different levels of FVC. Similar trends of decreasing differences with increasing age were noticed in the comparison of the predicted values for FEV1 and for the ratio FEV1/FVC. The predicted equations of QUANJER et al. [6] are commonly used in Europe and several studies have indicated that these equations significantly underestimate predicted FEV1 and FVC [12-15]. The present results confirm this indication. Possible causes, such as population/selection criteria, cohort effect and technical factors, remain uncertain. Both smokers and former smokers were included in the present study, because there was no significant effect nor was there an age-related effect of smoking on prediction values. This is surprising, because several studies did show a negative effect of smoking on predicted values [15] especially on predicted FEV1 and to a lesser extent on FVC. In this study, however, 39\% of the smokers were former smokers and stopped smoking $\geqslant 6$ months ago, which may explain the absence of a smoking effect.

Comparison of the face mask prediction equations of the maximal respiratory pressures with the predicted equations of WiLson et al. [8] is more difficult, because of the different explanatory variables. The difference in the final prediction equations cannot be explained by the statistical method being used, because the same variables i.e. age, height and weight, were included in the stepwise regression analyses. In this study, weight and age are significant in predicting maximal respiratory pressures (table 5).

The usefulness of maximal respiratory pressures is often debated because of the remarkably large interstudy variability in reference values in the literature [4, 7, 8, 16-19]. Koulouris et al. [20] and TUlly et al. [21] reported that maximal respiratory pressures depend much on the type of mouthpiece being used. The tube mouthpiece used by RingQVist [19], by BLACK and HYATT [4] and by RoCHESTER and ARORA [22] showed higher values than the flanged mouthpiece used by WILSON et al. [8], by LEECH et al. [17] and by VINCKEN et al. [7]. COOK et al. [16] suggested that higher expiratory pressures would be obtained using a tube-type mouthpiece, because it prevented air leakage around the mouthpiece, whereas KoULOURIS et al. [20] claimed that the manner in which the mouthpiece is used is important. The present data matched that of KoulOURIS et al. [20] because audible air leakage was an exclusion criteria in this study. In a few subjects, the presence of a moustache or beard precluded a proper sealing of the mask against the face. In these cases unnoticed leakage could not be excluded and therefore these subjects were withdrawn from this study.

Next to the type of mouthpiece connection, measurement of maximal respiratory pressures depends strongly on the skill of the investigator, population features and sample size. Moreover, interindividual factors as degrees of cooperation and coordination of the different respiratory muscles seem to be of great importance. In this study, the face mask devices were held by the investigator instead of the subjects, because patients with neuromuscular disease often have weakness of the arm muscles. This lack of control of the subject, being connected to the apparatus may preclude a real maximal effort. The same investigator performed all measurements to avoid possible interinvestigator bias. Both smokers and nonsmokers were included in this study. In line with the literature on reference values $[4,5,7,8]$, smoking status was not significant in predicted values of MIP and MEP.

A marked between-subject variability is seen throughout the literature $(25-40 \%)$ and was noticed in this study as well. To date, the best explanation is that it may reflect the different (use of) musculature of individuals [5] and the uncontrollable aspect of the voluntary effort by the subject. When taking the population and the technique into account, the present face mask data matched best with those of WILSON et al. [8], who had a similar population and methodology. The results show that measurements obtained using the face mask manometer are closely related to those obtained by the flanged mouthpiece as in the VINCKEN et al. [7] and WILSON et al. [8] studies. Although MEP values obtained with a face mask device are lower, this will not be of clinical importance if the appropriate reference ranges are used. Moreover, the most important information in individual patients is obtained by monitoring intraindividual changes in MIP and MEP over time. In this study the within-subject variability is much smaller compared with the CVs for MEP of $7.1 \%$ and for MIP of $10.2 \%$ in the study by WILSON et al. [8].

FIZ et al. [23] suggested the technique of manually holding the lips around the mouthpiece in patients with facial weakness to prevent air leakage. Some prefer the sniff nasal inspiratory pressure in assessing inspiratory muscle force in patients. CHAUDRI et al. [24] used a tight-fitting face mask to measure VC, and both MIP and MEP in some of the patients with difficulty in inserting or holding the mouthpiece, but refrained from commenting on the reference values.

The present study showed that using a face mask is an adequate method for ventilatory assessment in healthy adult persons at an outpatient clinic. The use of a face mask is recommended in patients with neuromuscular disease or more specifically in patients with facial weakness for screening purposes. It is a simple and effective alternative method, which can be most useful in monitoring changes in patients. Furthermore, it can be used for studies on natural course and respiratory function in neuromuscular disease. Finally, this study confirms the importance of using appropriate prediction values.

\footnotetext{
Acknowledgements. The authors would like to thank L.M. Haegens and M. Verbruggen for their excellent technical support and wish to acknowledge C. Smeets and O.J. Vogels for their valuable advise.
}

\section{References}

1. Heijdra YF, Dekhuijzen PN, van Herwaarden CL, Folgering HT. Differences between sniff mouth pressures and static maximal inspiratory mouth pressures. Eur Respir J 1993; 6: 541-546.

2. Polkey MI, Green M, Moxham J. Measurement of respiratory muscle strength. Thorax 1995; 50: 1131-1135.

3. Wijkstra PJ, van der Mark TW, Boezen M, van Altena R, Postma DS, Koeter GH. Peak inspiratory mouth pressure in healthy subjects and in patients with COPD. Chest 1995; 107 : 652-656.

4. Black LF, Hyatt RE. Maximal respiratory pressures: normal 
values and relationship to age and sex. Am Rev Respir Dis 1969; 99: 696-702.

5. Bruschi C, Cerveri I, Zoia MC, et al. Reference values of maximal respiratory mouth pressures: a population-based study. Am Rev Respir Dis 1992; 146: 790-793.

6. Quanjer PH, Tammeling GJ, Cotes JE, Pedersen OF, Peslin $\mathrm{R}$, Yernault JC. Lung volumes and forced ventilatory flows. Report Working Party Standardization of Lung Function Tests, European Community for Steel and Coal. Official Statement of the European Respiratory Society. Eur Respir J Suppl 1993; 16: 5-40.

7. Vincken W, Ghezzo H, Cosio MG. Maximal static respiratory pressures in adults: normal values and their relationship to determinants of respiratory function. Bull Eur Physiopathol Respir 1987; 23: 435-439.

8. Wilson SH, Cooke NT, Edwards RH, Spiro SG. Predicted normal values for maximal respiratory pressures in Caucasian adults and children. Thorax 1984; 39: 535-538.

9. Fiz JA, Haro M, Aguilar J, et al. Spirometry and maximal respiratory pressures in patients with facial paralysis. Chest 1993; 103: 170-173.

10. Lyall RA, Donaldson N, Polkey MI, Leigh PN, Moxham J. Respiratory muscle strength and ventilatory failure in amyotrophic lateral sclerosis. Brain 2001; 124: 2000-2013.

11. Bland JM, Altman DG. Statistical methods for assessing agreement between two methods of clinical measurement. Lancet 1986; 1: 307-310.

12. Brandli O, Schindler C, Kunzli N, Keller R, Perruchoud AP. Lung function in healthy never smoking adults: reference values and lower limits of normal of a Swiss population. Thorax 1996; 51: 277-283.

13. Castellsague J, Burgos F, Sunyer J, Barbera JA, Roca J. Prediction equations for forced spirometry from European origin populations. Barcelona Collaborative Group on Reference Values for Pulmonary Function Testing and the Spanish Group of the European Community Respiratory Health Survey. Respir Med 1998; 92: 401-407.
14. Langhammer A, Johnsen R, Gulsvik A, Holmen TL, Bjermer L. Forced spirometry reference values for Norwegian adults: the Bronchial Obstruction in Nord-Trondelag Study. Eur Respir J 2001; 18: 770-779.

15. Roca J, Burgos F, Sunyer J, et al. References values for forced spirometry. Group of the European Community Respiratory Health Survey. Eur Respir J 1998; 11: 1354 1362.

16. Cook C, Mead J, Orzalesi MM. Static volume pressure characteristics of the respiratory system during maximum efforts. J Appl Physiol 1964; 19: 1016-1021.

17. Leech JA, Ghezzo H, Stevens D, Becklake MR. Respiratory pressures and function in young adults. Am Rev Respir Dis 1983; 128: 17-23.

18. McElvaney G, Blackie S, Morrison NJ, Wilcox PG, Fairbarn MS, Pardy RL. Maximal static respiratory pressures in the normal elderly. Am Rev Respir Dis 1989; 139: 277-281.

19. Ringqvist T. The ventilatory capacity in healthy subjects. An analysis of causal factors with special reference to the respiratory forces. Scand J Clin Lab Invest Suppl 1966; 88: 5179.

20. Koulouris N, Mulvey DA, Laroche CM, Green M, Moxham J. Comparison of two different mouthpieces for the measurement of Pimax and Pemax in normal and weak subjects. Eur Respir J 1988; 1: 863-867.

21. Tully K, Koke K, Garshick E, Lieberman SL, Tun CG, Brown R. Maximal expiratory pressures in spinal cord injury using two mouthpieces. Chest 1997; 112: 113-116.

22. Rochester DF, Arora NS. Respiratory muscle failure. Med Clin North Am 1983; 67: 573-597.

23. Fiz JA, Carreres A, Rosell A, Montserrat JM, Ruiz J, Morera JM. Measurement of maximal expiratory pressure: effect of holding the lips. Thorax 1992; 47: 961-963.

24. Chaudri MB, Liu C, Watson L, Jefferson D, Kinnear WJ. Sniff nasal inspiratory pressure as a marker of respiratory function in motor neuron disease. Eur Respir $J$ 2000; 15: $539-542$. 